\title{
Processing of a Free Word Order Language: The Role of Syntax and Context
}

\author{
Natalia Slioussar
}

Published online: 8 July 2011

(C) The Author(s) 2011. This article is published with open access at Springerlink.com

\begin{abstract}
In languages with flexible constituent order (so-called free word order languages), available orders are used to encode given/new distinctions; they therefore differ not only syntactically, but also in their context requirements. In Experiment 1, using a self-paced reading task, we compared Russian S V IO DO (canonical), DO S V IO and DO IO V S constructions in appropriate vs. inappropriate contexts (those that violated their context requirements). The context factor was significant, while the syntax factor was not. The less pronounced context effect evidenced in previous studies (e.g., Kaiser and Trueswell in Cognitioin 94:113-147, 2004) might be due to the use of shorter target sentences and less extensive contexts. We also demonstrated that the slow-down starts at the first contextually inappropriate constituent, which shows that the information about context requirements is taken into account immediately, but that it develops faster on preverbal subjects and postverbal indirect objects (occupying their canonical positions) than on preverbal indirect objects (occupying a noncanonical position, or scrambled). In Experiment 2, these findings were replicated for IO S V DO and IO DO V S orders. S V IO DO orders with a continuation were used to show that there is no additional effect of inappropriate context at the end of the sentence.
\end{abstract}

Keywords Sentence processing $\cdot$ Word order $\cdot$ Scrambling $\cdot$ Context $\cdot$ Russian

\section{Introduction}

Languages differ in the amount of constituent order flexibility they permit. Changing constituent order in English $(1 \mathrm{a}, \mathrm{b})$ also changes the grammatical relations between constituents (i.e., 'who did what to whom').

N. Slioussar $(\varangle)$

Utrecht institute of Linguistics OTS, Trans 10, Utrecht 3512 JK, The Netherlands

e-mail: slioussar@gmail.com

N. Slioussar

Department of General Linguistics, St. Petersburg State University, Universitetskaja emb., 7-9,

St. Petersburg 199034, Russia 
1. a. The girl saw a dog.

b. The dog saw a girl.

In many other languages, different orders can be used in the same sentence without the grammatical relations between constituents being changed. This phenomenon is traditionally called free word order (this term might be confusing because no language allows changing the order of all words in every sentence, rather, many languages have flexible constituent order). As examples (2a, b) show, Russian is one of these languages. Case marking on the nouns, although it is sometimes ambiguous, helps in figuring out who did what to whom. Russian has no definite and indefinite articles, but as we will see below, similar distinctions are encoded by constituent order alternations.

2. a. Devočk-a uvidela sobak-u.

girl-NOM saw dog-ACC

b. Sobak-u uvidela devočk-a. dog-ACC saw girl-NOM

As noted by many authors coming from various frameworks (e.g., Hajičová et al. 1998; Kiss 1995; Lambrecht 1994; Mathesius 1947; Reinhart 2006; Rizzi 1997; Steedman 2000), different constituent orders reflect the information structure of the sentence, dividing it into given and new information, topic and focus. If we put aside very rare cases of fronted foci, (2b) signals that the object is given and the subject is new (2a), the so-called canonical order, has several interpretations: Either both constituents are new, or both are given, or the subject is given and the object is new. Consequently, these orders have different context requirements. E.g., (2a) can be used in zero context (i.e. when all information is new), whereas using (2b) in such a context will create a mismatch between the context and the information structure this order encodes. In other words, its context requirements will be violated.

In syntactic literature, the term scrambling coined by Ross (1967) is widely used to describe the constituent order alternations presented above (for some languages, like German or Dutch, two types of reordering, scrambling and topicalization, are usually distinguished, while for others, like Russian or Finnish, one general term is introduced). In some models, noncanonical structures are derived from the canonical one, while the others do not support this view, assuming that different constituent orders are base-generated. Abels (in press) provides an extensive overview and comparison of various approaches.

Most psycholinguistic studies of different constituent orders have focused on their syntactic properties, ignoring the context factor. Canonical and noncanonical structures from different languages were compared in zero context, and the latter were found to be more difficult to process (e.g., Bader and Meng 1999; Erdocia et al. 2009; Frazier and Flores d'Arcais 1989; Hyönä and Hujanen 1997; Miyamoto and Takahashi 2002, 2004; Stojanović 1999; Vasishth 2002). This was explained by the increased syntactic complexity of noncanonical orders and often taken as a proof of the psycholinguistic reality of syntactic operations deriving these orders from the canonical one.

However, we noted above that noncanonical orders are infelicitous in zero context, which violates their context requirements, and this factor should also be taken into account. But context-sensitive studies of scrambling are very rare. Kaiser and Trueswell (2004) compared Finnish SVO and OVS structures in appropriate and inappropriate contexts. In Finnish, as in most other free word order languages, the vast majority of narrative sentences have a 'given-new' constituent order. So appropriate contexts presupposed such an order in target constructions, while inappropriate ones presupposed a 'new-given' order-i.e., essentially violating the context requirements of target sentences. Kaiser and Trueswell used the selfpaced reading method, which is also used in our experiments and is described in detail in 
"Procedure". Their study showed that noncanonical constructions in appropriate contexts were processed faster than those in inappropriate contexts, but were still slower than the canonical order.

In another self-paced reading experiment (Sekerina 2003), Russian PP S V IO DO PP and PP DO S V IO PP constructions were compared in isolation and in the same context. PP stands for prepositional phrase - i.e., a noun phrase with a preposition. IO and DO denote indirect object and direct object. Since the context did not vary, the study demonstrated only that it had an overall facilitation effect for processing of both sentence types. Two ERP studies (Bornkessel and Schlesewsky 2006; Bornkessel et al. 2003) compared German SVO and OSV embedded clauses in isolation and in various question-answer contexts. In such experiments, reading times are not measured, so direct comparison with the studies mentioned above is impossible.

Notably, the participants of Kaiser and Trueswell (2004) experiment could notice that they dealt with the 'new-given' constituent order only at the last word of the sentence. Thus, it was impossible to examine how the effect of inappropriate context develops: Does it appear immediately or at the end of the sentence, and does it develop similarly on different constituents or not? The present study aimed to answer this question by looking at longer constructions in Russian and by using more extensive context sentences.

\section{Experiment 1}

Method

Participants

28 Russian undergraduate students (20 female and 8 male) participated in the experiment.

\section{Design and Materials}

We compared Russian S V IO DO, DO S V IO, and DO IO V S constructions. S V IO DO is the canonical order in Russian (e.g., Shvedova 1980; Sirotinina 1965). In those syntactic models where noncanonical orders are derived, DO IO V S is derived from the canonical order by more steps than is DO S V IO. Thus DO IO V S is expected to be more difficult to process if these operations indeed cause a computational overload.

The design was analogous to the one used by Kaiser and Trueswell (2004), but the context sentences established two constituents in the following target sentence as given. Contexts presupposing a 'given-given-new' constituent order in target constructions were taken to be appropriate, while contexts presupposing 'new-given-given' or 'given-new-given' orders were used as inappropriate. We designed 20 crucial items consisting of a target sentence in three constituent orders, as in $(3 \mathrm{a}-\mathrm{c})$, and three context sentences. The full list is given in the "Appendix".

3. a. Danja Kašin podaril Maše Smolinoj pljuševogo slona.

[Danya Kashin]-NOM gave [Masha Smolina]-DAT [plush elephant]-ACC

b. Pljuševogo slona Danja Kašin podaril Maše Smolinoj.

c. Pljuševogo slona Maše Smolinoj podaril Danja Kašin.

'Danya Kashin (proper name) gave Masha Smolina (proper name) a/the plush elephant' 
Table 1 A translation of one set of target and context sentences in seven experimental conditions

\begin{tabular}{lll}
\hline Condition & Context sentence & Target sentence \\
\hline 1. C in C & $\begin{array}{l}\text { Danya Kashin congratulated Masha } \\
\text { Smolina on March 8 }\end{array}$ & $\begin{array}{c}\text { [Danya Kashin]-NOM gave [Masha } \\
\text { Smolina]-DAT [plush } \\
\text { elephant]-ACC }\end{array}$ \\
2. N1 in N1 & On March 8, Danya Kashin bought a & [Plush elephant]-ACC [Danya \\
& plush elephant and a box of candies & Kashin]-NOM gave [Masha \\
& On March 8, Masha Smolina & Sinat-DAT \\
3. N2 in N2 & received a plush elephant and a box & Smolina]-DAT gave [Danya \\
& of candies & Kashin]-NOM \\
4. C in N1 & As in (2) & $\begin{array}{c}\text { As in (1) } \\
\text { As in (1) }\end{array}$ \\
5. C in N2 & As in (3) & As in (2) \\
6. N1 in C & As in (1) & As in (3) \\
7. N2 in C & As in (1) & \\
\hline
\end{tabular}

The three constituent orders in the target sentences were dubbed ' $\mathrm{C}$ ', 'N1' and 'N2' (from canonical and noncanonical). The appropriate context for an ' $\mathrm{N} 1$ ' target construction was also marked as 'N1' etc. To create inappropriate contexts, we presented target constructions in the contexts devised for other constituent orders. Seven experimental conditions are presented in Table 1 using a translation of one set of target and context sentences.

To guarantee that all given entities are equally recoverable from the context, we used literal repetition. We tried to find phrases that allow for it more naturally, like plush elephant or first and last names (as opposed to, e.g., industrious boy).

Every participant saw each experimental item in one of the seven conditions. Items presented to each participant were balanced with respect to appropriate vs. inappropriate contexts and canonical vs. scrambled target sentences, and their sequence was randomized. As a result, ' $\mathrm{C}$ in $\mathrm{C}$ ' condition (i.e., the canonical order in appropriate context) was two times more frequent than the other conditions.

We decided that the sentences in our study exhibited considerable syntactic diversity, so we could refrain from using filler items. In fact, we wanted to make the experiment as short as possible because unnatural conditions could cause fatigue in our informants - namely, that they would stop perceiving pairs of sentences as coherent stories and being surprised when this coherence is disrupted. This concern is supported by the fact that in Experiment 2, where we had to use fillers, all effects were less pronounced.

\section{Procedure}

The experiment was run on a PC using Presentation software. Each trial consisted of the participant's silently reading a two-sentence story and answering a comprehension question. The sentences appeared one at a time. Context and target sentences were masked; questions and answers were not. The participant pressed a key to reveal a portion of text (a constituent: a subject, an object, a verb) such that each key press revealed further text and masked the previously revealed text. Presentation software allows measuring the time between each key press with $1 \mathrm{~ms}$ accuracy, thus registering reading times for every constituent. After the context and target sentences, a question was shown. Then, after the next key press, two possible answers appeared on the right and on the left of the screen, and the participant could choose by pressing the key labeled 'left' or 'right'. The left-right distribution of correct and incorrect 
answers was randomized, and half of the questions were about context sentences. Then the participant pressed a key to move onto the next item. Experimental items were preceded by three practice trials.

This method, termed self-paced reading task, is widely used in experiments assessing localized processing difficulty in comprehension. We chose it to make our results comparable to those obtained in the previous studies mentioned in "Introduction". It must be noted that this method imposes some artificial restrictions on the process of reading. Most important, the readers cannot come back to previous portions of text, which they tend to do under natural conditions. However, several authors have directly compared the reading times obtained with this method to eye movement reading times (e.g., Ferreira and Henderson 1990; Garnsey et al. 1997; Trueswell et al. 1993). Similar patterns of localized difficulty were found, indicating that the method can be felicitously used to study such phenomena.

\section{Analysis}

We analyzed participants' question-answering accuracy and reading times. The raw reading times (per constituent) were trimmed in the following way. First, we dropped one RT of 83 ms (the next minimal RT was $269 \mathrm{~ms}$ ). Second, the mean RT plus three SDs (combining all RTs in all conditions) was approximately equal to $1600 \mathrm{~ms}$, and we adjusted all longer RTs to $1600 \mathrm{~ms}$. In total, about $1.7 \%$ of the data was adjusted. All participants answered at least $86 \%$ of the questions correctly (93\% on average). Approximately half of the incorrect answers were about context sentences. Given the low number of relevant errors (less than 5\%), a breakdown of RTs into correct and incorrect question trials was not done.

We calculated overall reading times of target sentences (sums of RTs per constituent) and compared them for different constituent orders and for appropriate vs. inappropriate contexts to establish the relative importance of syntax and context factors. Target sentences with the same lexical material were used in different conditions, so, unlike Kaiser and Trueswell (2004), we did not need frequency matching between subjects, direct objects, and indirect objects, which would be prohibitively difficult for two-word constituents. Since we did not do frequency matching, neither did we adjust reading times for string length when analyzing the results. This is usually done to make the comparison between different constituents possible by controlling the length factor, but in our case the frequency factor would remain uncontrolled anyway. Therefore, reading times per constituent were compared only for identical sentences presented in appropriate vs. inappropriate contexts, to see how the effect of the inappropriate context develops.

\section{Results and Discussion}

The mean overall reading times of target sentences are presented in Fig. 1 and listed in Table 2.

The difference between the three constituent orders was very small, while inappropriate contexts (ICs) caused a significant slow-down in target sentences, as compared to appropriate contexts (ACs) $(F 1[1,194]=9.00, p<0.01 ; F 2[1,138]=10.04, p<0.01)$. There was no interaction between syntax and context factors. IC sentences that had a 'new-given-given' constituent order were read slower than the ones with a 'given-new-given' order, but this difference was not significant. The difference between ' $\mathrm{C}$ in $\mathrm{C}$ ' vs. ' $\mathrm{C}$ in N2' conditions was marginally significant $(F 1[1,54]=3.95, p=0.05 ; F 2[1,38]=4.58, p=0.04)$, and other differences between conditions were not significant.

Reading times per constituent are presented in Figs. 2, 3, 4 and listed in Table 3. 


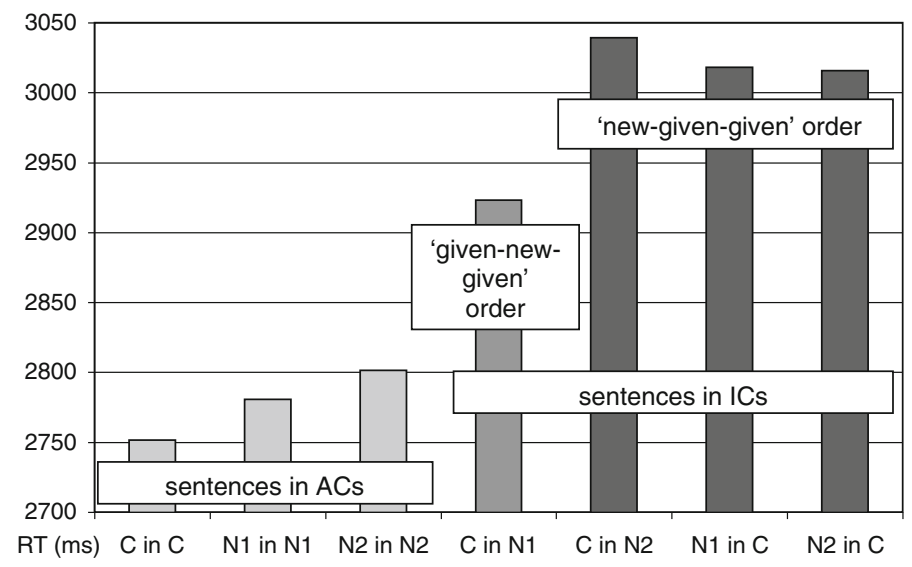

Fig. 1 Experiment 1: mean overall reading times of target sentences per condition

Table 2 Mean overall reading times for different groups of target sentences in Experiment 1

\begin{tabular}{ll}
\hline Groups of sentences & RT (ms) \\
\hline 'C' sentences (S V IO DO) & 2,867 \\
'N1' sentences (DO S V IO) & 2,899 \\
'N2' sentences (DO IO V S) & 2,909 \\
Sentences in ACs & 2,771 \\
Sentences in ICs & 2,999 \\
'C in C' condition & 2,752 \\
'N1 in N1' condition & 2,781 \\
'N2 in N2' condition & 2,801 \\
'C in N1' condition & 2,923 \\
'C in N2' condition & 3,039 \\
'N1 in C' condition & 3,018 \\
'N2 in C' condition & 3,016 \\
\hline
\end{tabular}

The first constituent was always read significantly faster when it was given $(F 1[1,54] \geq$ 8.92, $p<0.01 ; F 2[1,38] \geq 7.92, p<0.01$ for all pairs). This is an expected result: Apart from the possible sentence-level effects of given and new information, repeated words are typically read faster than unrepeated ones (see Traxler et al. 2000).

There was a marginally significant difference at the verb between ' $\mathrm{C}$ in N2' sentences starting with a new subject and ' $\mathrm{C}$ in $\mathrm{C}$ ' and ' $\mathrm{C}$ in $\mathrm{N1}$ ' sentences starting with a given subject $(F 1[1,54]=3.54, p=0.06 ; F 2[1,38]=4.25, p=0.05 ; F 1[1,54]=3.74$, $p=0.06 ; F 2[1,38]=3.34, p=0.07$, respectively).

Indirect objects in ' $\mathrm{C}$ ' and 'N2' sentences and subjects in 'N1' sentences were crucial for our experiment. They were the first given constituents following new information in three IC conditions (' $\mathrm{C}$ in N2', 'N1 in C' and ' $\mathrm{N} 2$ in C'). In AC sentences, these constituents were also given, but appropriately (i.e. they did not follow new constituents), so potential differences between AC and IC conditions can be explained only by the context factor. 


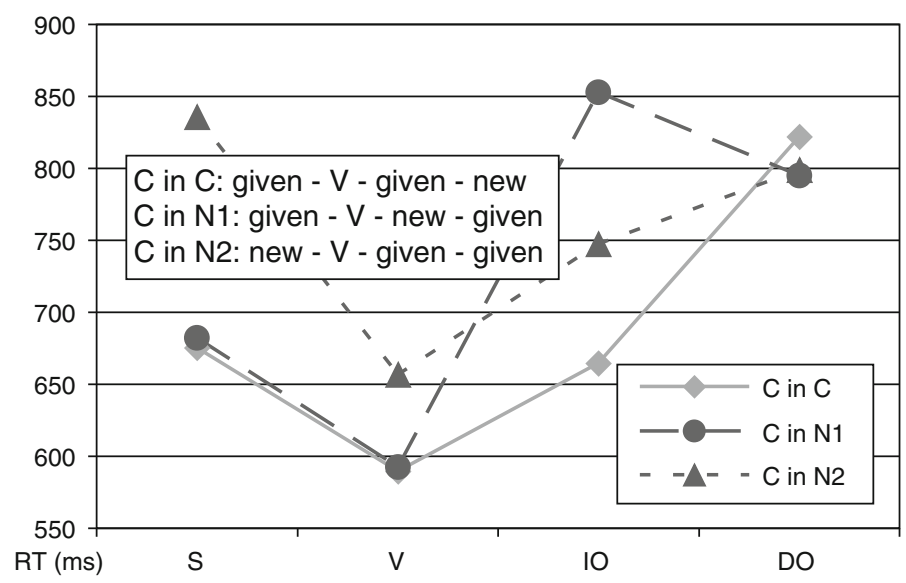

Fig. 2 'C' Sentences in Experiment 1: mean reading times per constituent

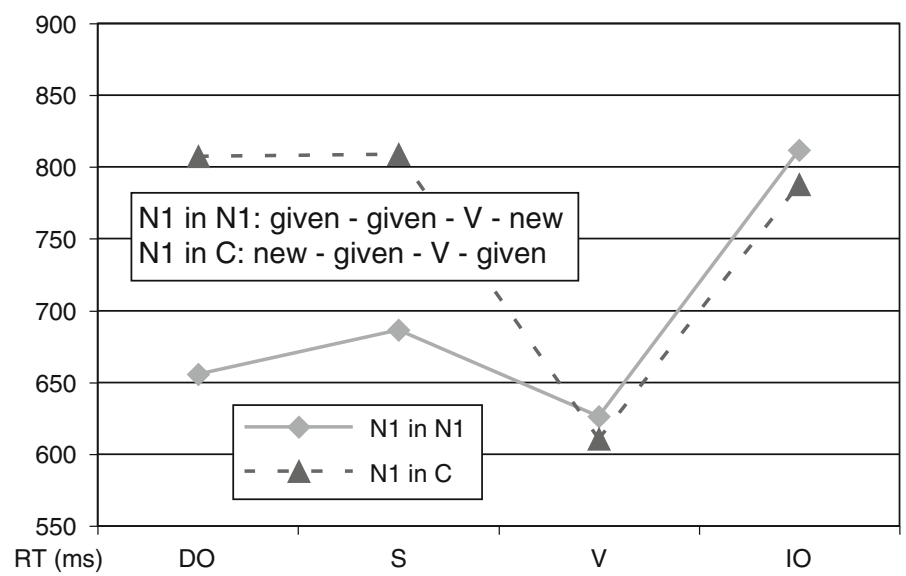

Fig. 3 'N1' Sentences in Experiment 1: mean reading times per constituent

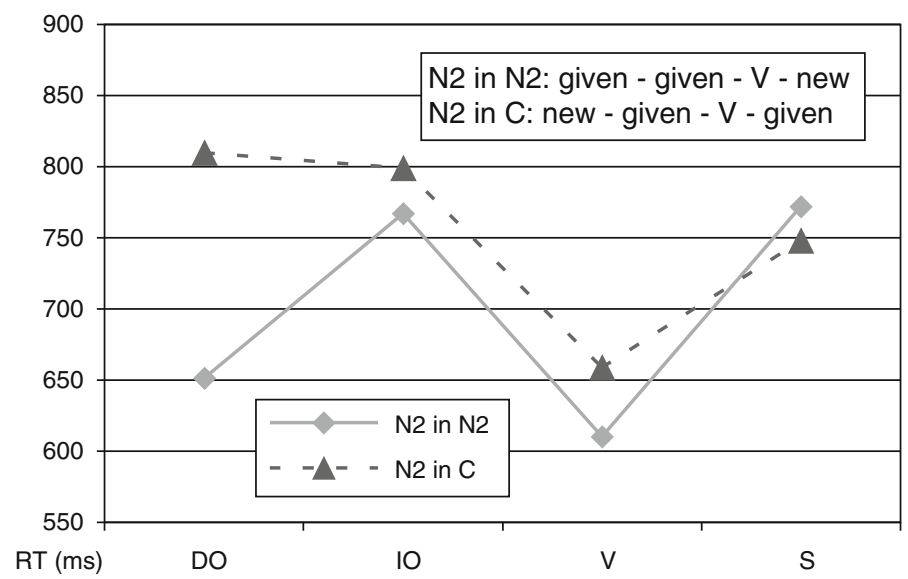

Fig. 4 'N2' Sentences in Experiment 1: mean reading times per constituent 
Table 3 Mean reading times per constituent for target sentences in Experiment 1

\begin{tabular}{|c|c|c|c|c|c|c|c|c|c|}
\hline & $\begin{array}{l}\mathrm{C} \text { in } \mathrm{C} \\
\mathrm{RT}(\mathrm{ms})\end{array}$ & $\begin{array}{l}\mathrm{C} \text { in N1 } \\
\mathrm{RT}(\mathrm{ms})\end{array}$ & $\begin{array}{l}\mathrm{C} \text { in N2 } \\
\mathrm{RT}(\mathrm{ms})\end{array}$ & & $\begin{array}{l}\text { N1 in N1 } \\
\text { RT (ms) }\end{array}$ & $\begin{array}{l}\text { N1 in C } \\
\text { RT (ms) }\end{array}$ & & $\begin{array}{l}\mathrm{N} 2 \text { in N2 } \\
\mathrm{RT}(\mathrm{ms})\end{array}$ & $\begin{array}{l}\mathrm{N} 2 \text { in } \mathrm{C} \\
\mathrm{RT}(\mathrm{ms})\end{array}$ \\
\hline S & 676 & 682 & 836 & DO & 656 & 808 & DO & 652 & 810 \\
\hline V & 590 & 593 & 657 & $\mathrm{~S}$ & 687 & 809 & IO & 767 & 799 \\
\hline IO & 665 & 853 & 748 & $\mathrm{~V}$ & 626 & 611 & $\mathrm{~V}$ & 611 & 659 \\
\hline DO & 822 & 795 & 799 & IO & 812 & 788 & $\mathrm{~S}$ & 772 & 748 \\
\hline
\end{tabular}

The results are dissimilar across conditions. The difference at postverbal indirect objects in the ' $C$ ' sentences is statistically significant $(83 \mathrm{~ms}, F 1[1,54]=4.42, p=$ $0.04 ; F 2[1,38]=6.72, p=0.01)$, and so is the difference at preverbal subjects in the 'N1' sentences $(120 \mathrm{~ms}, F 1[1,54]=7.74, p<0.01 ; F 2[1,38]=8.44, p<0.01)$. In the ' $\mathrm{N} 2$ in C' condition, there was a small slow-down at the preverbal indirect object (about 30 $\mathrm{ms}$ ), which subsequently increased at the verb (about $50 \mathrm{~ms}$ ), but did not reach statistical significance.

Since information about context requirements and their violation cannot be instantly accessible in some constructions, but not in the others, we conclude that inappropriate contexts were detected immediately. The difference between preverbal subjects and postverbal indirect objects vs. preverbal indirect objects is that the former were in their canonical positions, while the latter were not (in syntactic terms, they underwent scrambling). To check whether this is indeed the cause of the difference, we examined other constructions in Experiment 2.

In the ' $\mathrm{C}$ in $\mathrm{N} 1$ ' condition, the postverbal indirect object was new and, as expected, was processed significantly longer than the appropriately given indirect object in ' $\mathrm{C}$ in $\mathrm{C}$ ' sentences $(F 1[1,54]=14.06, p<0.01 ; F 2[1,38]=14.65, p<0.01)$. It was also read slower than the inappropriately given indirect object in ' $\mathrm{C}$ in N2' sentences, but the difference was not significant.

Finally, the fourth constituents were new in the AC group and given in the IC group, so no direct comparison is possible. Still, it is notable that there is no statistical and even no visible difference between the AC and IC groups. It means that the inappropriate context effect was strong enough to 'balance out' an extremely robust lexical repetition effect.

\section{Experiment 2}

Method

\section{Participants}

30 Russian undergraduate students (18 female and 12 male) participated in the experiment.

\section{Design and Materials}

Design and materials were the same as in Experiment 1 with the following modifications. First, we used two different noncanonical orders: IO S V DO and IO DO V S (dubbed 'N3' and 'N4'), to see whether the findings from Experiment 1 would be replicated. Second, in Experiment 1 final constituents could not be directly compared in appropriate vs. 
inappropriate contexts. So we added continuations to canonical orders, forming 'S V IO DO Tail' structures (dubbed 'CT'), as in (4), to see whether there would be an additional effect of inappropriate context at the end of the sentence, when all information contained in it is assumed to undergo final integration in the current discourse model.

4. Danja Kašin podaril Maše Smolinoj pljuševogo slona ot imeni vsex mal'chikov.

[Danya Kashin]-NOM gave [Masha Smolina]-DAT [plush elephant]-ACC on behalf of all boys

We presented ' $\mathrm{CT}$ ' sentences only in appropriate contexts and in inappropriate contexts presupposing 'new-given-given' constituent order. Thus, there were six conditions in this experiment. We also dropped two items from Experiment 1 that tended to be processed longer than the others. All experimental items are listed in the "Appendix".

Finally, although no exact frequency counts exist, constructions starting with indirect objects were definitely less frequent than the ones starting with direct objects, so we decided to use fillers. These fillers also consisted of two sentences followed by a question. The second sentences contained one or two given constituents and had the following constituent order distribution: 9 S V DO PP, 9 S V PP DO (canonical orders, depending on the nature of the prepositional phrase), 3 DO S V PP, 3 PP S V DO, 3 DO PP V S, 3 PP DO V S.

\section{Procedure}

The procedure was the same as in Experiment 1.

\section{Analysis}

We analyzed participants' question-answering accuracy and reading times in the same way as in Experiment 1. The raw reading times were trimmed as follows. We dropped one RT of $16 \mathrm{~ms}$ (the next minimal RT was $330 \mathrm{~ms}$ ). The mean RT plus three SDs was approximately equal to $1,500 \mathrm{~ms}$, and we adjusted all longer RTs (about 1.6\%) to 1,500 ms. All participants answered at least $84 \%$ of the questions correctly (92\% on average). So, as in Experiment 1 , a breakdown of RTs into correct and incorrect question trials was not done.

\section{Results and Discussion}

The mean overall reading times of target sentences (sums of RTs per constituent) are presented in Fig. 5 and listed in Table 4.

In this experiment, different constituent orders cannot be compared because the sentences in different conditions do not contain the same lexical material: 'CT' structures (S V IO DO Tail) are longer than 'N3' (IO S V DO) and 'N4' (IO DO V S) ones. As before, the sentences in appropriate contexts (ACs) were read significantly faster than the sentences in inappropriate contexts (ICs) $(F 1[1,178]=4.93, p=0.03 ; F 2[1,106]=4.43, p=0.04)$. No other comparison was significant.

The results for RTs per constituent are presented in Figs. 6, 7, 8 and listed in Table 5.

As in Experiment 1, the first constituent was read significantly faster in all constituent orders when it was given than when it was new $(F 1[1,58] \geq 4.86, p \leq 0.03 ; F 2[1,34] \geq$ $4.39, p \leq 0.04$ for all pairs), and there was almost no difference between fourth constituents in $\mathrm{AC}$ and IC conditions. The difference at the verb in the ' $\mathrm{CT}$ ' sentences did not reach significance. 


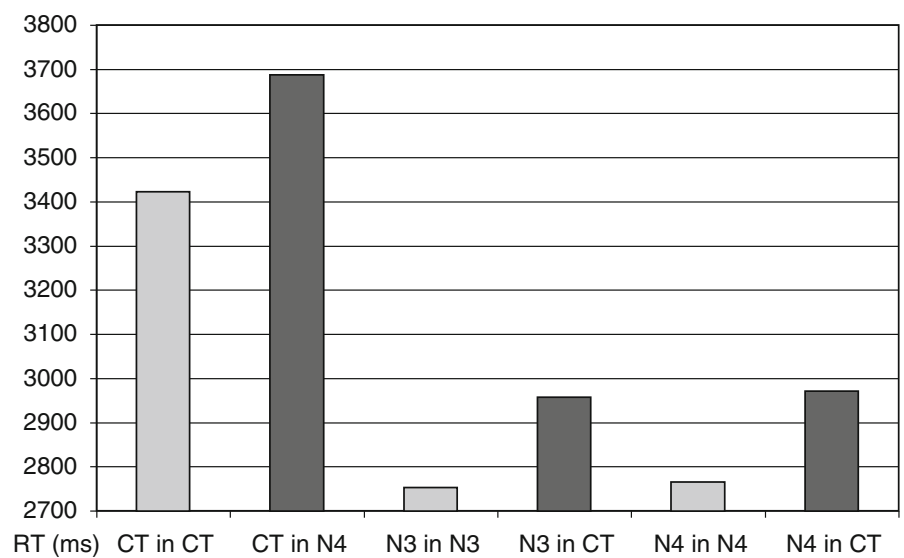

Fig. 5 Experiment 2: mean overall reading times of target sentences per condition

Table 4 Mean overall reading times for different groups of target sentences in Experiment 2

\begin{tabular}{ll}
\hline Groups of sentences & RT (ms) \\
\hline Sentences in ACs & \\
Sentences in ICs & 3,422 \\
'CT in CT' condition (S V IO DO Tail) & 3,687 \\
'CT in N4' condition (S V IO DO Tail) & 2,753 \\
'N3 in N3' condition (IO S V DO) & 2,957 \\
'N3 in CT' condition (IO S V DO) & 2,765 \\
'N4 in N4' condition (IO DO V S) & 2,971 \\
'N4 in CT' condition (IO DO V S)
\end{tabular}

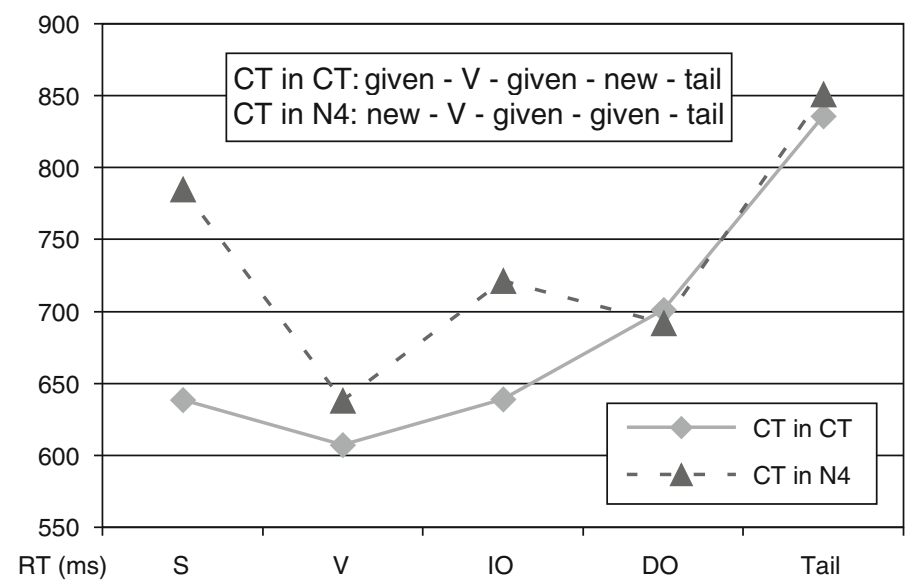

Fig. 6 'CT' Sentences in Experiment 2: mean reading times per constituent 


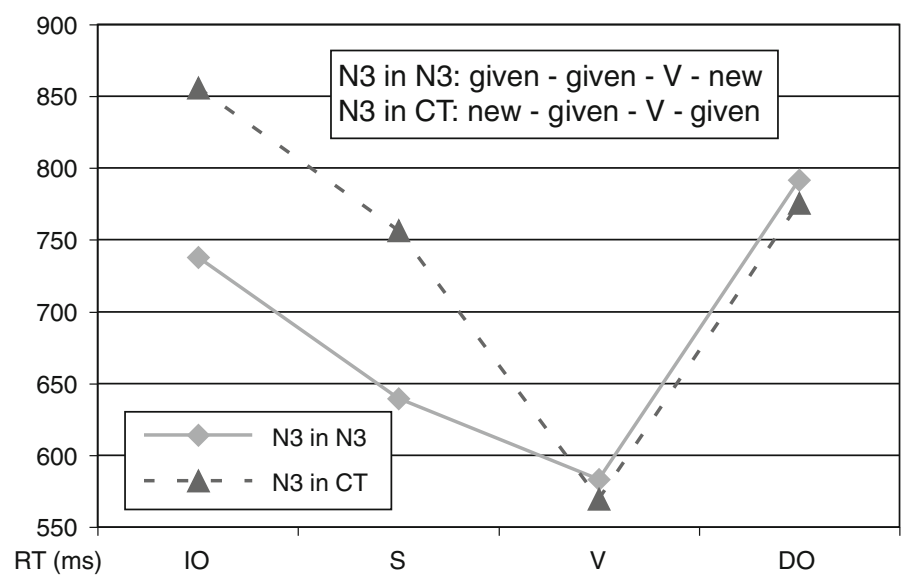

Fig. 7 'N3' Sentences in Experiment 2: mean reading times per constituent

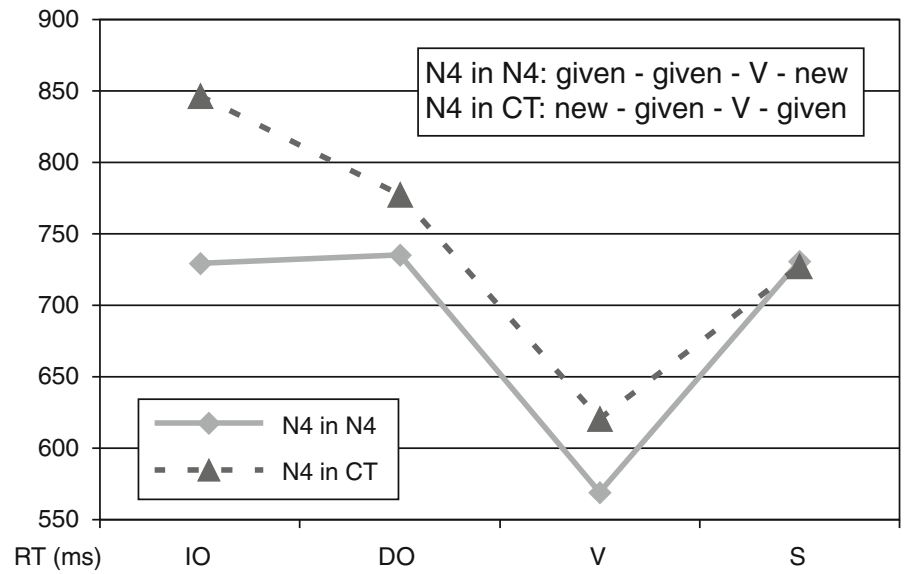

Fig. 8 'N4' Sentences in Experiment 2: mean reading times per constituent

Table 5 Mean reading times per constituent for target sentences in Experiment 2

\begin{tabular}{|c|c|c|c|c|c|c|c|c|}
\hline & $\begin{array}{l}\text { CT in CT } \\
\text { RT (ms) }\end{array}$ & $\begin{array}{l}\text { CT in N4 } \\
\text { RT (ms) }\end{array}$ & & $\begin{array}{l}\text { N3 in N3 } \\
\text { RT (ms) }\end{array}$ & $\begin{array}{l}\text { N3 in CT } \\
\text { RT (ms) }\end{array}$ & & $\begin{array}{l}\text { N4 in N4 } \\
\text { RT (ms) }\end{array}$ & $\begin{array}{l}\text { N4 in CT } \\
\text { RT (ms) }\end{array}$ \\
\hline $\mathrm{S}$ & 638 & 785 & IO & 738 & 856 & IO & 729 & 847 \\
\hline V & 607 & 638 & $\mathrm{~S}$ & 640 & 757 & DO & 735 & 777 \\
\hline IO & 639 & 721 & $\mathrm{~V}$ & 583 & 569 & V & 569 & 620 \\
\hline DO & 701 & 692 & DO & 792 & 776 & S & 731 & 727 \\
\hline Tail & 836 & 851 & & & & & & \\
\hline
\end{tabular}


Looking at indirect objects in 'CT' sentences, subjects in 'N3' sentences and direct objects in 'N4' sentences, we can determine that the pattern discovered in Experiment 1 was replicated. The slow-down developed immediately at constituents occupying their canonical positions: at subjects $(F 1[1,58]=8.49, p<0.01 ; F 2[1,34]=5.88, p=0.02)$ and indirect objects $(F 1[1,58]=3.67, p=0.06 ; F 2[1,34]=3.97, p=0.05)$. At direct objects occupying a noncanonical position there was a difference of about $40 \mathrm{~ms}$ that subsequently increased at the verb $(50 \mathrm{~ms})$, but did not reach statistical significance.

Finally, the last portion of the sentences in ' $\mathrm{CT}$ in CT' and ' $\mathrm{CT}$ in N4' conditions (dubbed 'tail') elicited roughly the same RTs. This answers the second question asked in Experiment 2: There is no additional effect of inappropriate context at the end of the sentence.

\section{General Discussion}

In this study, we compared the influence of the syntax factor (canonical vs. noncanonical constituent orders) and the context factor (appropriate vs. inappropriate contexts) on the processing of Russian sentences. The context factor proved to be significant, while the difference between various constituent orders was not statistically significant. The context effect was much more pronounced than in similar previous studies - potentially, because we used longer target sentences and more extensive contexts, which allowed the context effect to develop fully.

Can this be taken as an indication that the scrambling operation postulated in various syntactic models has no psycholinguistic reality? It seems to us that these results have no bearing on this question. Any model that takes the full syntactic complexity of languages like Russian into account and supposes that scrambling operations are psycholinguistically real will have to conclude that they induce a minimal processing load on the basis of purely syntactic considerations alone. Many Russian sentences are assumed to contain multiple instances of scrambling. If processing this operation indeed induced a significant processing load, such sentences would be especially difficult to comprehend, like multiple center embeddings, and would not be very frequent. This is definitely not the case: They are rather common in written and colloquial Russian (e.g., Slioussar 2007) and are processed effortlessly. Obviously, our results presented above cannot be used to tell whether scrambling operations are psycholinguistically real, but very easy to process, or if they have no psycholinguistic reality. However, some results discussed below may bear on this question.

The importance of the context factor can be explained by the fact that constituent order alternations are used specifically to establish the informational properties of different constituents (given/new, topic/focus). Thus context requirement violations are expected to cause serious processing problems. The canonical order has certain context requirements, as does any other order. The only difference is that the contexts where it can be felicitously uttered are more numerous and include the zero context. Consequently, inappropriate contexts are expected to affect processing of all constituent orders. This is exactly what we found.

Unlike previous studies, our study could also analyze the timing of the inappropriate context effect. We found out that it appeared immediately at the first contextually inappropriate constituent and that there was no additional slow-down at the end of the sentence, when all information contained in it is assumed to undergo final integration in the current discourse model. This is in line with earlier findings showing that context plays an important role in incremental processing (e.g., Altmann and Steedman 1988; Crain 1980; Crain and Steedman 1985). 
We also discovered that the inappropriate context effect depends on the syntactic nature of the constituent, a finding not previously suggested. It develops immediately at preverbal subjects and postverbal indirect objects, occupying their canonical positions, and more slowly at preverbal direct and indirect objects, which occupy a noncanonical position. These results can be taken as an indication that scrambling is psycholinguistically real: Constituents in canonical and noncanonical positions showed distinct properties. However, these results cannot be used to distinguish between various syntactic approaches to scrambling-in particular, those in which noncanonical orders are derived from canonical ones by syntactic movement and those in which the relations between these orders are established by different operations.

\section{Appendix: Experimental Materials for Experiments 1 and 2}

Experiments 1 and 2 used the same target sentences, but in different word orders: 'C' (S V IO DO), 'N1' (DO S V IO), 'N2' (DO IO V S) in Experiment 1 and 'CT' (S V IO DO Tail), 'N3' (IO S V DO), 'N4' (IO DO V S) in Experiment 2. For the first item, we present the full experimental paradigm. For the remaining critical items, only the S V IO DO (Tail) version of the target sentence is given. Items 3 and 12 were not used in Experiment 2.

1. 'C' target sentence:

Danja Kašin podaril Maše Smolinoj pljuševogo slona.

[Danya Kashin]-NOM gave [Masha Smolina]-DAT [plush elephant]-ACC

' $\mathrm{C}$ ' context sentence (used as appropriate context for the ' $\mathrm{C}$ ' target sentence):

Na 8 marta Danja Kašin pozdravil Mašu Smolinu ${ }^{1}$.

'On March 8 Danya Kashin congratulated Masha Smolina.'

'N1' target sentence:

Pljuševogo slona Danja Kašin podaril Maše Smolinoj. [plush elephant]-ACC [Danya Kashin]-NOM gave [Masha Smolina]-DAT

'N1' context sentence:

Na 8 marta Danja Kašin kupil pljuševogo slona i korobku konfet.

'On March 8 Danya Kashin bought a plush elephant and a box of candies.'

'N2' target sentence:

Pljuševogo slona Maše Smolinoj podaril Danja Kašin.

[plush elephant]-ACC [Masha Smolina]-DAT gave [Danya Kashin]-NOM

'N2' context sentence:

Na 8 marta Maša Smolina polučila pljuševogo slona i korobku konfet.

'On March 8 Masha Smolina received a plush elephant and a box of candies.'

'CT' target sentence:

Danja Kašin podaril Maše Smolinoj pljuševogo slona ot imeni vsex mal'chikov.

[Danya Kashin]-NOM gave [Masha Smolina]-DAT [plush elephant]-ACC on behalf of all boys

'CT' context sentence: same as 'C' context sentence

'N3' target sentence:

Maše Smolinoj Danja Kašin podaril pljuševogo slona.

[Masha Smolina]-DAT [Danya Kashin]-NOM gave [plush elephant]-ACC

1 It can be noted that given constituents in the target sentence do not always appear in the same case as in the context sentence. We analyzed our data to ensure that this did not lead to any reaction time differences. 
'N3' context sentence:

Na 8 marta Danja Kašin pozdravil Mašu Smolinu i Marinu Vydrinu.

'On March 8 Danya Kashin congratulated Masha Smolina and Marina Vydrina.'

'N4' target sentence:

Maše Smolinoj pljuševogo slona podaril Danja Kašin.

[Masha Smolina]-DAT [plush elephant]-ACC gave [Danya Kashin]-NOM

'N4' context sentence:

Na 8 marta Maša Smolina i Marina Vydrina polučili pljuševyx slonov.

'On March 8 Masha Smolina and Marina Vydrina received plush elephants.'

2. Učitel'nica matematiki zadala desjatiklassnikam složnuju zadaču (i provela kontrol'nuju). [math teacher]-NOM set [tenth-grade students]-DAT [difficult problem]-ACC (and conducted a test)

3. Semiklassnica Nataša predstavila Lene Zubovoj Pašu Petrova. [seventh-grade girl Natasha]-NOM introduced [Lena Zubova]-DAT [Pasha Petrov]-ACC

4. Nikolaj Pavlovič rasskazal Ol'ge Viktorovne glupuju istoriju (davjas' ot smexa).

[Nikolay Pavlovich]-NOM told [Olga Viktorovna]-DAT [stupid story]-ACC (stifling laughter)

5. Vanja Petuxov vernul Sone Sobolevoj francuzskuju knigu (i ugostil konfetami).

[Vanya Petukhov]-NOM returned [Sonya Soboleva]-DAT [French book]-ACC (and treated (her) to candies)

6. Lena Maslova otnesla bol'noj babuške banku meda (kupiv ee na rynke).

[Lena Maslova]-NOM brought [ill granny]-DAT [jar of honey]-ACC (having bought it on the market)

7. Vasina babuška pokazala Taninoj mame staruju fotografiju (i soobščila vse novosti).

[Vasya's granny]-NOM showed [Tanya's mother]-DAT [old photo]-ACC (and told all the news)

8. Anna Timofeevna otpravila Zine Smirnovoj bol'šuju posylku (i pozdravila po telephonu). [Anna Timofeevna]-NOM mailed [Zina Smirnova]-DAT [big parcel]-ACC (and congratulated her on the phone)

9. Učastkovyj vrač propisal pensionerke Larinoj lakričnuju miksturu (i izmeril davlenie). [family doctor]-NOM prescribed [pensioner Larina]-DAT [licorice extract]-ACC (and measured blood pressure)

10. Dima Simonov poslal Alene Marfenko ljubovnuju zapisku (v nadušennom konverte).

[Dima Simonov]-NOM sent [Alena Marfenko]-DAT [love letter]-ACC (in a scented envelope)

11. Direktor školy vručil pobeditelju olimpiady početnuju gramotu (i proiznes reč').

[school director]-NOM handed [competition winner]-DAT [honorary diploma]-ACC (and gave a speech)

12. Andrej Sorokin prodemonstriroval Nine Manevič dressirovannuju sobačku.

[Andrey Sorokin]-NOM demonstrated [Nina Manevich]-DAT [trained dog]-ACC

13. Seržant Petrov vydal soldatam-novobrancam novuju uniformu (i raspredelil zadanija). [sergeant Petrov]-NOM gave [new soldiers]-DAT [new uniform]-ACC (and assigned tasks)

14. Dmitrij Aleksandrovič prodal Evgeniju Daniloviču staruju mašinu (rasxvaliv ee dostoinstva). 
[Dmitry Aleksandrovich]-NOM sold [Evgeny Danilovich]-DAT [old car]-ACC (having praised its merits)

15. Mitja Andreev kupil Olen'ke Somovoj sdobnuju buločku (v dorogom kafe).

[Mitya Andreev]-NOM bought [Olenka Somova]-DAT [sweet bun]-ACC (in the expensive café)

16. Babuška Vera sšila malen'komu Leše piratskuju šljapu (iz černoj koži). [granny Vera]-NOM sewed [little Lesha]-DAT [pirate hat]-ACC (from black leather)

17. Vova Nečaev pridumal Šuriku Sazonovu klichku 'Kolobok' (i dolgo draznil ego).

[Vova Nechaev]-NOM invented [Shurik Sazonov]-DAT [nickname 'gingerbread boy']-ACC (and teased him for a long time)

18. Inna Pavlovna zažarila Petru Semenoviču moločnogo porosenka (na ego den' roždenija). [Inna Pavlovna]-NOM roasted [Petr Semenovich]-DAT [suckling pig]-ACC (on his birthday)

19. Pavlik Ivanov podložil Natke Davydovoj bol'šuju knopku (i namazal stul kleem).

[Pavlik Ivanov]-NOM put under [Natke Davydova]-DAT [big drawing pin]-ACC (and smeared (her) chair with glue)

20. Vodoprovodčik Vasja ustanovil Elizavete Vladimirovne novuju vannu (vmesto staroj razvaliny).

[Plumber Vasya]-NOM installed [Elizaveta Vladimirovna]-DAT [new bathtub]-ACC (instead of the old ruin)

Acknowledgments This work was supported in part by the Rubicon grant 446-07-019 from the Netherlands Organization for Scientific Research (NWO). I have benefited from the comments and help of many linguists while working on this paper, and I am particularly grateful to Frank Wijnen.

Open Access This article is distributed under the terms of the Creative Commons Attribution Noncommercial License which permits any noncommercial use, distribution, and reproduction in any medium, provided the original author(s) and source are credited.

\section{References}

Abels, K. (in press). Word order. In A. Alexiadou \& T. Kiss (Eds.), Syntax: Ein Handbuch zeitgenössischer Forschung (2nd Ed). Berlin: Mouton de Gruyter.

Altmann, G. T. M., \& Steedman, M. (1988). Interaction with context during human sentence processing. Cognition, 30, 191-238.

Bader, M., \& Meng, M. (1999). Subject-object ambiguities in German embedded clauses: An across-the-board comparison. Journal of Psycholinguistic Research, 28, 121-144.

Bornkessel, I., \& Schlesewsky, M. (2006). The role of contrast in the local licensing of scrambling in German: Evidence from online comprehension. Journal of Germanic Linguistics, 18, 1-43.

Bornkessel, I., Schlesewsky, M., \& Friederici, A. (2003). Contextual information modulates initial processes of syntactic integration: The role of inter-versus intrasentential predictions. Journal of Experimental Psychology: Learning, Memory and Cognition, 29, 871-882.

Crain, S. (1980). Pragmatic constraints on sentence comprehension. Doctoral dissertation, University of California, Irvine.

Crain, S., \& Steedman, M. (1985). On not being led up the garden path: The use of context in the psychological syntax processor. In D. R. Dowty, L. Karttunen, \& A. M. Zwicky (Eds.), Natural language parsing (pp. 320-358). Cambridge, UK: Cambridge University Press.

Erdocia, K., Laka, I., Mestres-Misse, A., \& Rodriguez-Fornells, A. (2009). Syntactic complexity and ambiguity resolution in a free word order language: Behavioral and electrophysiological evidences from Basque. Brain and Language, 109, 1-17. 
Ferreira, F., \& Henderson, J. M. (1990). Use of verb information in syntactic parsing: Evidence from eye movements and word-by-word self-paced reading. Journal of Experimental Psychology: Learning, Memory and Cognition, 16, 555-568.

Frazier, L., \& Flores d'Arcais, G. B. (1989). Filler-driven parsing: A study of gap-filling in Dutch. Journal of Memory and Language, 28, 331-334.

Garnsey, S. M., Pearlmutter, N. J., Myers, E., \& Lotocky, M. A. (1997). The contributions of verb bias and plausibility to the comprehension of temporarily ambiguous sentences. Journal of Memory and Language, 37, 58-93.

Hajičová, E., Partee, B. H., \& Sgall, P. (1998). Topic-focus articulation, tripartite structures, and semantic content. Dordrecht: Kluwer.

Hyönä, J., \& Hujanen, H. (1997). Effects of case marking and word order on sentence parsing in Finnish: An eye fixation analysis. The Quarterly Journal of Experimental Psychology: A Human Experimental Psychology, 50, 841-858.

Kaiser, E., \& Trueswell, J. C. (2004). The role of discourse context in the processing of a flexible word-order language. Cognition, 94, 113-147.

Kiss, K. (Ed.) (1995) Discourse configurational languages. Oxford: Oxford University Press

Lambrecht, K. (1994). Information structure and sentence form. Cambridge, UK: Cambridge University Press.

Mathesius, V. (1947). Čeština a obecný jazykozpyt ('Czech language and general linguistics'). Praha: Melantrich.

Miyamoto, E., \& Takahashi, S. (2002). Sources of difficulty in processing scrambling in Japanese. In M. Nakayama (Ed.), Sentence processing in East-Asian languages (pp. 167-188). Stanford: CSLI Publications.

Miyamoto, E., \& Takahashi, S. (2004). Filler-gap dependencies in the processing of scrambling in Japanese. Language and Linguistics, 5, 53-166.

Reinhart, T. (2006). Interface strategies: Optimal and costly computations. Cambridge, MA: MIT Press.

Rizzi, L. (1997). The fine structure of the left periphery. In L. Haegeman (Ed.), Elements of grammar: Handbook in generative syntax (pp. 281-337). Dordrecht: Kluwer.

Ross, J. (1967). Constraints on variables in syntax. Doctoral dissertation, MIT press.

Sekerina, I. (2003). Scrambling and processing: Dependencies, complexity and constraints. In S. Karimi (Ed.), Scrambling and word order (pp. 301-324). Malden, MA: Blackwell.

Shvedova, N. Yu. (Ed.) (1980). Russkaja grammatika ('Russian grammar') Moscow: Nauka.

Sirotinina, O. B. (1965). Porjadok slov v russkom jazyke ('Word order in Russian'). Saratov: Saratov University Publishing House.

Slioussar, N. (2007). Grammar and information structure. A study with reference to Russian. Doctoral dissertation, Utrecht University. Utrecht: LOT Publications.

Steedman, M. (2000). Information structure and the syntax-phonology interface. Linguistic Inquiry, 31, 649-689.

Stojanović, D. (1999). Parsing and acquisition: Evidence from Serbo-Croatian. Doctoral Dissertation, University of Ottawa.

Traxler, M. J., Foss, D. J., Seely, R. E., Kaup, B., \& Morris, R. K. (2000). Priming in sentence processing: Intralexical spreading activation, schemas, and situation models. Journal of Psycholinguistic Research, 29, 581-595.

Trueswell, J. C., Tanenhaus, M. K., \& Kello, C. (1993). Verb-specific constraints in sentence processing: Separating effects of lexical preference from syntactic garden-paths. Journal of Experimental Psychology: Learning, Memory, and Cognition, 19, 528-553.

Vasishth, S. (2002). Working memory in sentence comprehension: Processing Hindi center embeddings. Doctoral Dissertation, Ohio State University. 